7-1-2017

\title{
The Antiproliferative and Apoptotic Effects of Apigenin on Glioblastoma Cells
}

Trevor Stump

Cedarville University, tstump@cedarville.edu

Brittany Santee

Cedarville University, brittanynsantee@cedarville.edu

Lauren P. Williams

Cedarville University, lpwilliams@cedarville.edu

Rachel Kunze

Cedarville University, rkunze@cedarville.edu

Chelsae Heinze

Cedarville University, cheinze@cedarville.edu

See next page for additional authors

Follow this and additional works at: http://digitalcommons.cedarville.edu/ pharmaceutical_sciences_publications

Part of the Pharmacy and Pharmaceutical Sciences Commons

\section{Recommended Citation}

Stump, Trevor; Santee, Brittany; Williams, Lauren P.; Kunze, Rachel; Heinze, Chelsae; Huseman, Eric; Gryka, Rebecca J.; Simpson, Denise; and Amos, Samson, "The Antiproliferative and Apoptotic Effects of Apigenin on Glioblastoma Cells" (2017). Pharmaceutical Sciences Faculty Publications. 174.

http://digitalcommons.cedarville.edu/pharmaceutical_sciences_publications/174

This Article is brought to you for free and open access by DigitalCommons@Cedarville, a service of the Centennial Library. It has been accepted for inclusion in Pharmaceutical Sciences Faculty Publications by an authorized administrator of

DigitalCommons@Cedarville.For more information, please contact digitalcommons@cedarville.edu. 


\section{Authors}

Trevor Stump, Brittany Santee, Lauren P. Williams, Rachel Kunze, Chelsae Heinze, Eric Huseman, Rebecca J. Gryka, Denise Simpson, and Samson Amos 


\title{
The antiproliferative and apoptotic effects of apigenin on glioblastoma cells
}

\author{
Trevor A. Stump, Brittany N. Santee, Lauren P. Williams, Rachel A. Kunze, Chelsae E. Heinze, \\ Eric D. Huseman, Rebecca J. Gryka, Denise S. Simpson and Samson Amos (iD \\ Department of Pharmaceutical Sciences, School of Pharmacy, Health Sciences Center, Cedarville University, Cedarville, OH, USA
}

\section{Keywords}

apigenin; apoptosis; epidermal growth factor receptor; glioblastoma; proliferation

\section{Correspondence}

Samson Amos, Department of Pharmaceutical Sciences, School of Pharmacy, Cedarville University, $251 \mathrm{~N}$. Main Street, Cedarville, OH 45314, USA. E-mail: samos@cedarville.edu

Received August 17, 2016

Accepted February 26, 2017

doi: $10.1111 /$ jphp. 12718

\begin{abstract}
Objectives Glioblastoma (GBM) is highly proliferative, infiltrative, malignant and the most deadly form of brain tumour. The epidermal growth factor receptor (EGFR) is overexpressed, amplified and mutated in GBM and has been shown to play key and important roles in the proliferation, growth and survival of this tumour. The goal of our study was to investigate the antiproliferative, apoptotic and molecular effects of apigenin in GBM.

Methods Proliferation and viability tests were carried out using the trypan blue exclusion, MTT and lactate dehydrogenase (LDH) assays. Flow cytometry was used to examine the effects of apigenin on the cell cycle check-points. In addition, we determined the effects of apigenin on EGFR-mediated signalling pathways by Western blot analyses.

Key findings Our results showed that apigenin reduced cell viability and proliferation in a dose- and time-dependent manner while increasing cytotoxicity in GBM cells. Treatment with apigenin-induced is poly ADP-ribose polymerase (PARP) cleavage and caused cell cycle arrest at the G2M checkpoint. Furthermore, our data revealed that apigenin inhibited EGFR-mediated phosphorylation of mitogen-activated protein kinase (MAPK), AKT and mammalian target of rapamycin (mTOR) signalling pathways and attenuated the expression of Bcl-xL. Conclusion Our results demonstrated that apigenin has potent inhibitory effects on pathways involved in GBM proliferation and survival and could potentially be used as a therapeutic agent for GBM.
\end{abstract}

\section{Introduction}

Glioblastoma (GBM) is a highly proliferative, infiltrative brain tumour that is resistant to currently available chemotherapy- and radiation-induced apoptotic tumour cell death. ${ }^{[1,2]}$ It is classified by the World Health Organization (WHO) as a grade IV tumour, ${ }^{[3]}$ and about fifteen per cent of all primary brain tumours are GBM. ${ }^{[4]}$ The majority of those diagnosed with glioblastoma will die within a year of diagnosis. ${ }^{[3]}$ It is also a heterogeneous tumour; meaning that each cell within the tumour may express distinct characteristics. ${ }^{[5]}$ Such distinct characteristics include, among others, mutations and overexpression of certain proteins.

Epidermal growth factor receptor (EGFR) is one of the proteins altered in GBM leading to a highly proliferative and treatment-resistant tumour. ${ }^{[1-3,6]}$ In particular, EGFR may play a key role in the pathogenesis of GBM, as lower grade gliomas do not have the EGFR overexpression that GBM commonly present with. ${ }^{[6]}$ EGFR signalling is involved in multiple signal transduction pathways, most notable of which involves activation of both the RAS/ MAPK and PI3K-AKT pathways, which provide key regulation of cell growth, proliferation and survival. ${ }^{[7]}$

Beyond this role, EGFR signalling also modulates tumour invasiveness by upregulating genes that code for matrix metalloproteinase (MMP). MMP plays a role in cell proliferation and migration when activated. $^{[5]}$ Characteristically, GBM is an incredibly invasive type of cancer, and EGFR overexpression may be involved in creating this key trait. ${ }^{[6]}$ Because of its importance to tumour regulation, EGFR pathways remain an attractive target in many types of cancer, including GBM, in spite of the fact that current EGFR targeted therapies have failed. $^{[7]}$ 
Mitogen-activated protein kinase (MAPK) and extracellular signal-regulated kinase (ERK) are both regulatory kinases important for cell proliferation through the modulation of the cell cycle. ${ }^{[5,7]}$ Inhibition of these kinases could contribute to a halt of the cell growth cycle and in turn, the inhibition of growth of cancer cells. The MAPK family includes three different groups: ERK/MAPK, p38 and Jun N-terminus kinase (JNK). ${ }^{[8]}$ The most studied part of the MAPK family is the ERK/MAPK portion, the activity of which is regulated by a variety of growth factors and mitogens. $^{[8]}$

Protein kinase B (AKT) is another important part of cell signalling within tumour cells. ${ }^{[7]}$ Mammalian target of rapamycin (mTOR) is a signalling molecule further downstream of the AKT pathway. mTOR has recently been shown to promote cancer cell growth and survival through AKT activation, an effect which adds to treatment resistance arising from the AKT pathway. ${ }^{[9]}$ The positive effects of mTOR on cancer cell survival, proliferation and malignancy are mediated although the activation of S6 Kinase (S6K) and the ability of S6K to increase the synthesis of protective and metabolic proteins. ${ }^{[10]}$

Another key biological feature characteristic of glioblastoma is decreased cell death (apoptosis, which is commonly referred to as programmed cell death). Apoptotic signalling is a vital component of our body's regulation of cell health by inducing the destruction of harmful cells. ${ }^{[1]}$ The process of apoptosis is triggered by the activation of signalling cascades that involve the cleavage of procaspases into matured active caspases. ${ }^{[11]}$ Initiator caspases upstream become activated by protein cleavage performed by active caspases, causing a downstream activation of executioner caspases. The executioner caspases in turn cleave and either destroy antiapoptotic protein or activate pro-apoptotic protein. The antiapoptotic protein is poly ADP-ribose polymerase (PARP). ${ }^{[12]}$ This enzyme detects, binds to, and repairs sites of DNA damage. ${ }^{[13-15]}$ When caspases are activated, they bind and cleave PARP thereby preventing DNA repair and inducing apoptotic cell death. For this reason, PARP serves as a marker of apoptosis. ${ }^{[14,15]}$ While PARP executes its antiapoptotic effects by repairing DNA damage and promoting cell growth, BCL-xL is another antiapoptotic protein that is targeted, cleaved and destroyed by caspases. BCL-xL inhibits apoptosis and promotes cell survival through the protection of cellular mitochondria and the prevention of the release of the caspase activating cytochrome C. ${ }^{[14,15]}$

Malignant gliomas are resistant to chemotherapy and radiation, and there is the need for the development of other small molecule inhibitors that can be used in the management of patients with glioma. Natural products present a vast array of chemicals that can be investigated for their potential therapeutic benefits. Flavonoids are natural<smiles>O=c1cc(-c2ccc(O)cc2)oc2cc(O)cc(O)c12</smiles>

Figure 1 Structure of apigenin.

compounds found in many plants and vegetables. They have been shown to possess a range of effects on biological systems. ${ }^{[16,17]}$ Apigenin (Figure 1) belongs to the flavone subclass of flavonoids. Apigenin has shown promising effects in the treatment of various cancers. ${ }^{[1-23]}$ Apigenin has demonstrated suppression of cancer signalling pathways and tumour cell adhesion on endothelial cells. Signalling pathways thought to be involved include JNK, ERK and AP-1. ${ }^{[24]}$ In other research studies, apigenin has exhibited anti-inflammatory effects and demonstrated benefit in metabolic syndrome via inhibition of the enzyme NAD+ase. ${ }^{[17,25]}$ Most relevant to this study, apigenin has demonstrated induction of apoptosis of certain cancer cells. ${ }^{[18-23]}$

The biological effects of apigenin on the survival, proliferation and EGFR-mediated GBM growth is not wellunderstood. The goal of this study is to investigate and further delineate the possible molecular pathways that are modulated in GBM by apigeni. This will provide us with an insight into the subtypes of GBM that may be susceptible to apigenin therapy.

\section{Materials and Methods}

\section{Cell lines}

The GBM cell lines U1242 MG and U87 MG and normal h astrocytes (NHA) were kindly supplied by Dr Isa M. Hussaini (University of Virginia, College of Medicine, Charlottesville). These cell lines were originally isolated from astrocytic tumours and were designated glioblastoma. Their characteristics were previously described by Hussaini et al. ${ }^{[26]}$ U1242 MG and U87 MG were maintained in Modified Eagle's Medium alpha (MEM-alpha; Gibco, Carlsbad, CA, USA) supplemented with 10\% foetal bovine serum and $1 \%$ penicillin and streptomycin. All cells were incubated at $37^{\circ} \mathrm{C}$ in a humidified atmosphere containing $5 \%$ carbon dioxide.

\section{Chemical/biological reagents materials}

Apigenin ( $\geq 98 \%$ purity) and erlotinib were obtained from Cayman Chemical (Ann Arbor, MI, USA). Phenylmethanesulfonyl fluoride (PMSF), sodium orthovanadate, and 
dimethyl sulfoxide (DMSO), alpha-tubulin, Hoechst 33342 and propidium iodide were purchased from Sigma-Aldrich (St. Louis, MO, USA). Peroxidase-conjugated affiniPure goat antirabbit IgG was purchased from Jackson ImmunoResearch Laboratories (West Grove, PA, USA). Penicillin/Streptomycin antibiotic and MEM-alpha (1X) were purchased from Gibco. Phospho-EGF receptor, phospho AKT and phospho-MAP kinase, PARP and Bcl-xL antibodies were purchased from Cell Signaling Technology Inc. (Danvers, MA, USA). Foetal bovine serum (FBS) was purchased from Biowest LLC (Riverside, MO, USA).

\section{Cell viability and proliferation tests}

Membrane integrity and cell viability of U1242 MG and U87 MG cells were evaluated after treatment with apigenin $(0-80 \mu \mathrm{M})$. U1242 MG and U87 MG cells were seeded at a density of $1 \times 10^{5}$ cells/well in a 6-well plate with or without apigenin for 48 and $72 \mathrm{~h}$. Cells were then harvested and resuspended in $1 \mathrm{ml}$ of serum free media. $100 \mu \mathrm{l}$ of cell suspension was stained with $100 \mu \mathrm{l}$ of $0.4 \%$ trypan blue solution. $20 \mu \mathrm{l}$ of the cell suspension was placed on to the haemocytometer and counted. The number of viable and non-viable cells/ $\mu$ l was determined. Three replicate experiments were performed for each analysis.

The effect of apigenin $(0-80 \mu \mathrm{M})$ and erlotinib $(10 \mu \mathrm{M})$ on cell proliferation was assessed using the MTT $(3-(4,5-$ dimethylthiazolyl-2)-2, 5-diphenyltetrazolium bromide) assay. Glioblastoma cells were seeded into 96-well plates at a density of $1 \times 10^{4}$ cells in the presence or absence of EGF $(25 \mathrm{ng} / \mathrm{ml})$. The 96-well plates were then incubated for 48 and $72 \mathrm{~h}$. After incubation, $20 \mu \mathrm{l}$ of MTT dye was added to each well of the 96-well plate, and incubated for $4 \mathrm{~h}$. Finally, $100 \mu \mathrm{l}$ of stop reagent was added to each well. The plates were incubated for at least $1 \mathrm{~h}$ at room temperature and then read at a wavelength of $560 \mathrm{~nm}$ using the Promega Glomax multidetection system. The optical density was used to calculate the rate of cell proliferation after exposure to different concentrations of apigenin. All experiments were performed in triplicate, and the mean for each experiment was calculated.

\section{Measurement and detection of cell apoptosis}

A lactate dehydrogenase $(\mathrm{LDH})$ assay was used to determine cytotoxicity. U1242 MG $\left(1 \times 10^{4}\right)$ cells/well were cultured in a 96-well plate and allowed to grow overnight. The next day the cells were treated with apigenin (0$80 \mu \mathrm{M})$ for $72 \mathrm{~h}$ per standard protocols. Release of LDH is an indicator of membrane integrity and hence, cell injury. The intracellular LDH release was measured at an absorbance of $490 \mathrm{~nm}$ using a Promega GloMax $^{\circledR}$-Multi
Detection System. The percentage of LDH release was calculated as: (LDH activity in media)/(LDH activity in media + intracellular LDH activity) $\times 100$. Each experiment was done independently three times.

Apoptosis staining was performed by using Hoechst 33342. U1242 MG cells were seeded in a 6-well-plate at a density of $1 \times 10^{5}$ cells/well and treated with various concentrations of apigenin $(0-80 \mu \mathrm{M})$. After $48 \mathrm{~h}$ of incubation, the cells were stained with Hoechst dye $(40 \mathrm{mg} / \mathrm{ml})$. The plates were kept in a dark room for $15 \mathrm{~min}$, which was followed by the addition of propidium iodide dye to each well. The plates were left in the dark room for another 15 min. After incubation, the cells were visualised under a Nikon fluorescence microscope with red and blue filters. Photomicrographs were taken under a fluorescent phasecontrast microscope at a magnification of $10 \times$ using the Nikon NIS Elements Imaging Software (version 4.0).

To determine the morphological effects of apigenin on normal human astrocytes (NHA), NHA cells were grown in 6-well plates and treated with DMSO as control and apigenin $(40 \mu \mathrm{M})$ for $48 \mathrm{~h}$. After incubation for $48 \mathrm{~h}$ the cells were imaged using the Nikon NIS Elements Imaging Software at a magnification of $10 \times($ version 4.0$)$.

\section{Western blot and protein analysis}

Following exposure to different concentrations of apigenin $(0-80 \mu \mathrm{M})$, erlotinib $(10 \mu \mathrm{M})$ and treatment with EGF (25 ng/ml), the cells were washed with cold phosphate buffered saline (PBS) containing $0.2 \mathrm{~mm}$ of sodium orthovanadate. The cells were lysed with Triton-X-100 lysis buffer containing $2 \mathrm{~mm}$ EDTA, $100 \mathrm{~mm} \mathrm{NaCl}, 0.2 \%$ NP-40, $2 \mathrm{mg} / \mathrm{ml}$ sodium orthovanadate and $1 \mathrm{X}$ protease cocktail inhibitor. Cells were centrifuged at $16000 \times \mathrm{g}$ for $5 \mathrm{~min}$ at $4{ }^{\circ} \mathrm{C}$. Protein concentration was determined using the BCA assay (Biorad, Hercules, CA, USA). Equal amounts of protein were boiled for $5 \mathrm{~min}$ in $5 \times$ sample buffer. Proteins were separated on $10 \%$ SDS-PAGE polyacrylamide gels. They were then electroblotted onto nitrocellulose membrane. Immunoblotting was performed using either a mouse monoclonal or rabbit polyclonal primary antibodies targeting MAPK, AKT, PARP and Bcl-xL. The membranes were then incubated with HRP-conjugated secondary antibody $(1: 2000)$ at room temperature for $1 \mathrm{~h}$ and subsequently analysed using the enhanced chemiluminescence (ECL) reagent (GE Healthcare Life Sciences, Pittsburgh, PA, USA) and visualised using the Alpha Innotech FluorChem FC2 (Cell Biosciences, Santa Clara, CA, USA).

\section{Flow cytometric analysis of cell cycle arrest}

DNA content after treatment with various concentrations of apigenin $(0-80 \mu \mathrm{M})$ was used to determine cell cycle 
distribution by propidium iodide (PI). U1242 MG cells were seeded in $100 \mathrm{~mm}$ dishes and cultured for $48 \mathrm{~h}$ in the presence or absence of apigenin. Adherent and floating cells were collected, centrifuged and washed with PBS. Cells were then fixed in $1 \mathrm{ml}$ of cold $70 \%$ ethanol. After standing
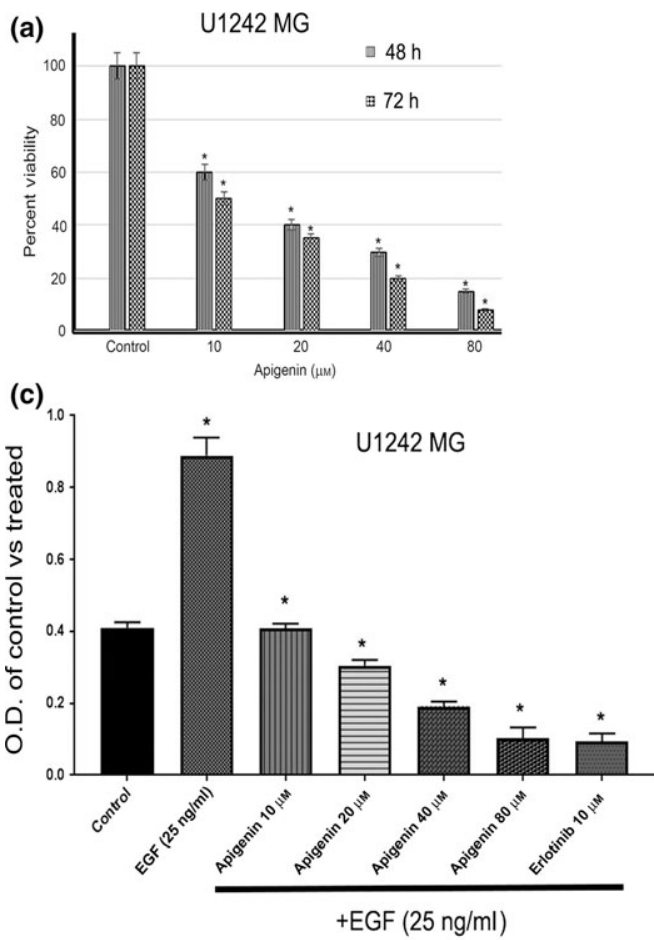

(e) $\mathrm{HO} 33342$
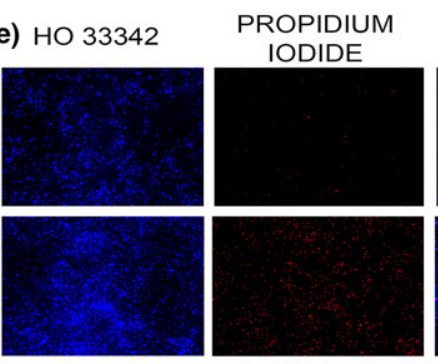

MERGE
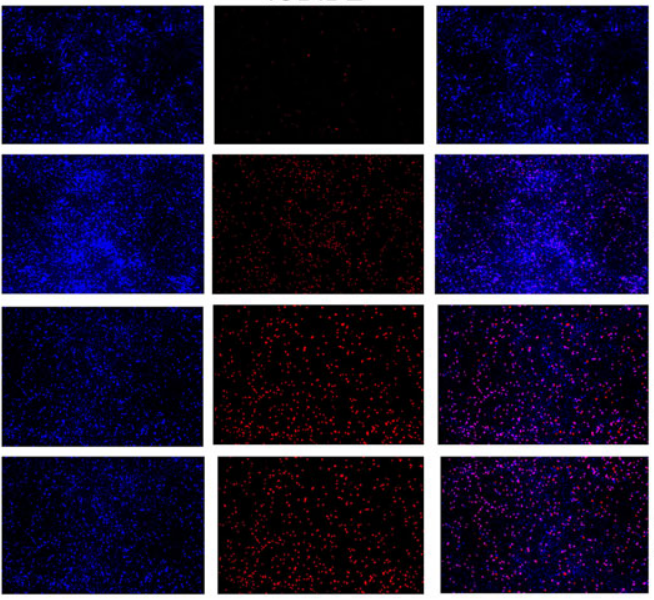

for $16 \mathrm{~h}$ at $4{ }^{\circ} \mathrm{C}$, cells were centrifuged and resuspended in $1 \mathrm{ml}$ of DNA staining solution $(5 \mu \mathrm{g} / \mathrm{ml}$ PI, $0.1 \%$ Triton-X $100,200 \mu \mathrm{g} / \mathrm{ml}$ of RNase A in PBS). PI-stained cells were analysed using the Becton Dickinson FACSCalibur, and data analysis was performed using the Cellquest software.

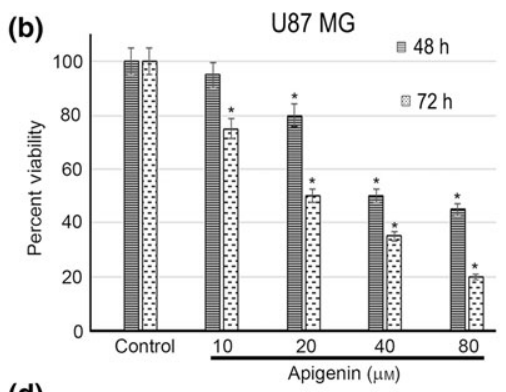

(d)
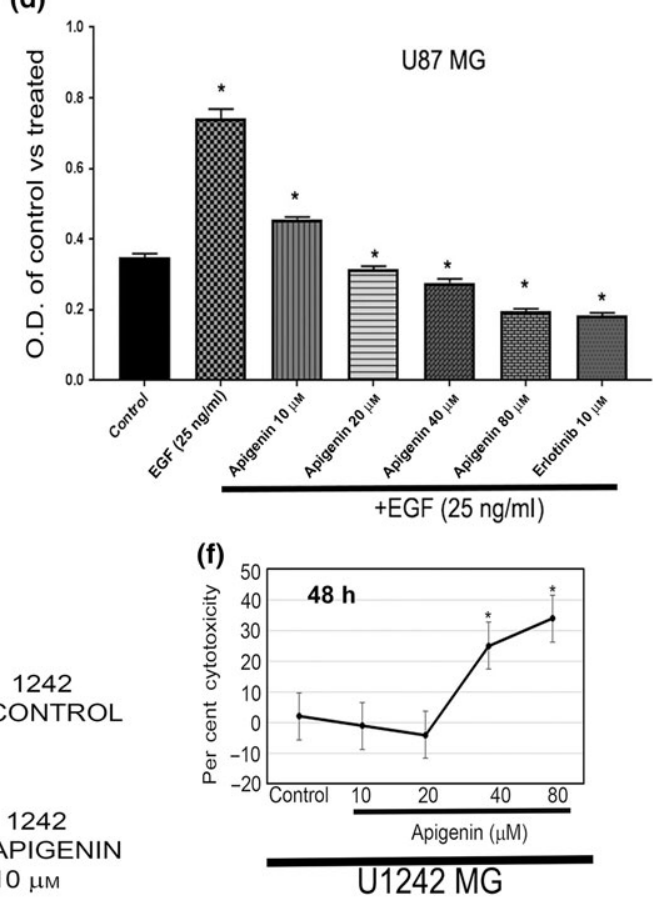

1242

CONTROL

1242

APIGENIN

$10 \mu \mathrm{m}$

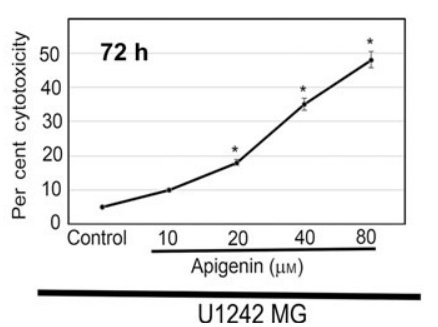

Figure 2 Effects of apigenin (0-80 $\mu \mathrm{M}$ ) on the viability of (a) U1242 MG cells after 48 and $72 \mathrm{~h}$ of treatment. (b) Effects of apigenin (0-80 $\mu \mathrm{M}$ ) on the viability of U87 MG cells after 48 and $72 \mathrm{~h}$ of treatment. All data are expressed as the mean \pm SD of experiments performed in triplicate. *Denotes significant $(P<0.05)$ difference in cell growth in treated cells compared to untreated control cells. (c) Effects of apigenin $(0,10,40,80 \mu \mathrm{m})$ and erlotinib $(10 \mu \mathrm{M})$ on epidermal growth factor receptor-mediated cell proliferation in U87 MG cells. (d) Effects of apigenin $(0,10,40,80 \mu \mathrm{M})$ and erlotinib $(10 \mu \mathrm{M})$ on epidermal growth factor receptor-mediated cell proliferation in U1242 MG. (e) Effects of apigenin $(0,10,40,80 \mu \mathrm{M})$ on the morphology of U1242 MG cells (Magnification $\times 10)$. ( $f$ ) Cytotoxicity of apigenin (0-80 $\mu \mathrm{M}$ ) in U1242 MG cells as measured by a lactate dehydrogenase assay after 48 and $72 \mathrm{~h}$ of treatment. All data are expressed as the mean \pm SD of experiments performed in triplicate. *Denotes significant $(P<0.05)$ difference in cell death in treated cells compared to untreated control cells. [Colour figure can be viewed at wileyonlinelibrary.com] 


\section{Statistical analysis}

When indicated, quantitative analysis was conducted using an analysis of variance (ANOVA) with a Bonferroni post hoc test $(\alpha=0.05)$. Statistics were analysed with IBM SPSS 23 (Chicago, IL, USA).

\section{Results}

\section{Effects of apigenin on cell viability}

To test the effects of apigenin on the viability of GBM cell lines, we used the trypan blue exclusion assay. The per cent viability in both the U1242 MG and U87 MG cell lines at 48 and $72 \mathrm{~h}$ post-treatment was quantified following exposure to increasing concentrations of apigenin $(0-80 \mu \mathrm{M})$ compared with control (DMSO). The effects of apigenin on U1242 MG and U87 MG cell lines were both concentration- and time-dependent. As the concentration of apigenin increased from 0 to $80 \mu \mathrm{M}$, the number of cells and per cent viability decreased (Figure $2 \mathrm{a}$ and $2 \mathrm{~b}$ ). Compared to the untreated control, U1242 MG cells treated with apigenin showed a significant $(P<0.05)$ decrease in cell viability after 48 and $72 \mathrm{~h}$ at all concentrations, while the U87 MG cells were less susceptible to the effects of apigenin at $10 \mu \mathrm{M}$ at the $48 \mathrm{~h}$ time point (Figure $2 \mathrm{~b}$ ) but were susceptible at the $72 \mathrm{~h}$ period. In addition, we also tested the effects of erlotinib $(10 \mu \mathrm{M})$ on EGF-mediated cell proliferation in GBM cells. We observed a robust inhibition of EGFRmediated cell proliferation in the presence of apigenin (10$80 \mu \mathrm{M})$ and erlotinib $(10 \mu \mathrm{M})$ in U1242 MG and U87 MG cells (Figure $2 \mathrm{c}$ and $2 \mathrm{~d}$ ).

\section{Cytotoxic effects of apigenin}

To test the cytotoxic effects of apigenin on GBM cells, we used the Hoechst-propidium iodide (HO-PI) inclusion/exclusion and LDH cellular level assays. The photomicrographs of Hoechst-PI staining are shown in Figure 2e. In the U1242 MG cell line, there was an increase in the number of cells that incorporated PI (nonviable; red cells) as compared to the cells that incorporated HO (viable; blue cells). We observed that the number of non-viable cells increased as the concentration of apigenin increased from the 0 (control) to concentrations of 10, 40 and $80 \mu \mathrm{M}$ (Figure $2 \mathrm{e})$.

The release of a considerable amount of $\mathrm{LDH}$ by a cell signifies a compromised and dying cell. We tested the effects of apigenin on the release of LDH and measured the content of LDH in the GBM medium using the LDH assay kit as described in the experimental section. Apigenin (40$80 \mu \mathrm{M})$ induced a significant cytotoxicity in the U1242 GBM cell line $(P<0.05)$ at 48 and $72 \mathrm{~h}$ (Figure $2 \mathrm{f}$ ). At
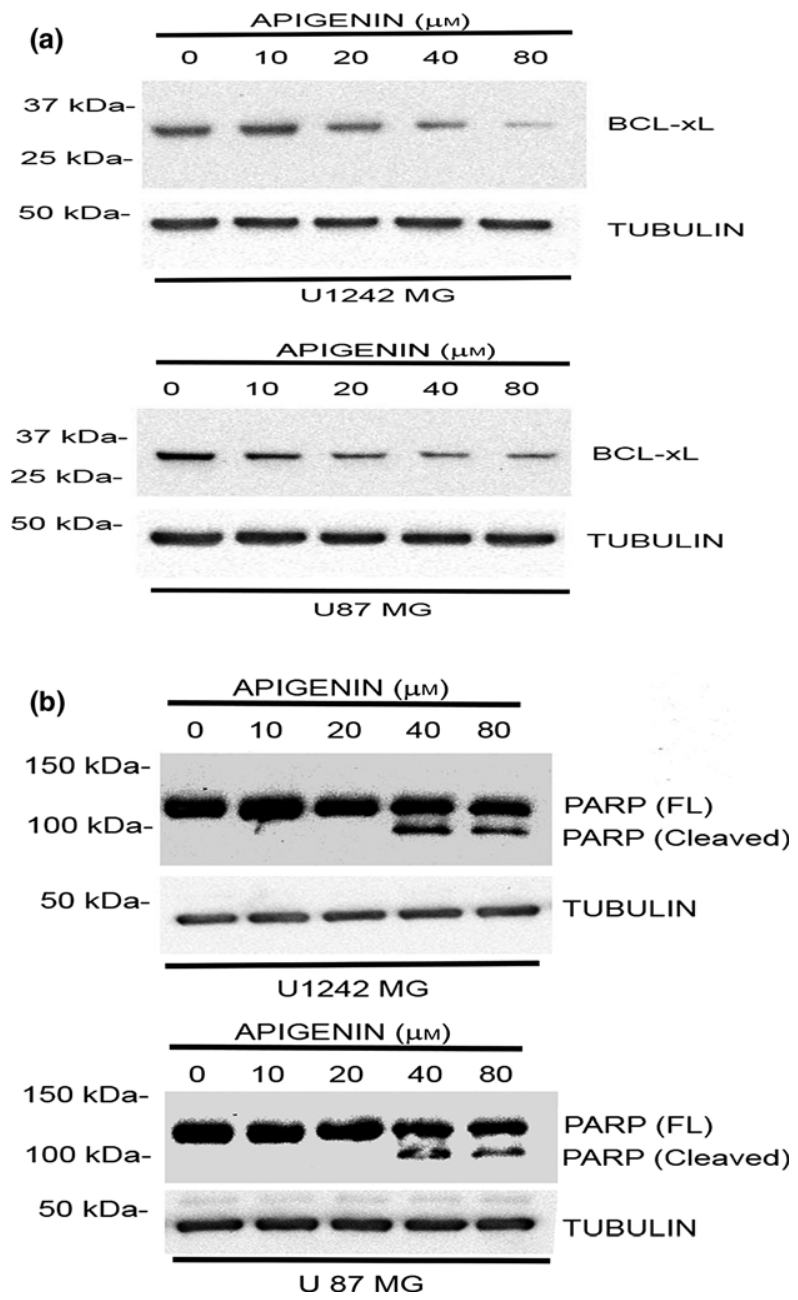

Figure 3 (a) Western blot analyses showing the effects of apigenin $(0-80 \mu \mathrm{M})$ on the expression of BCL-xL in U1242 MG and U87 MG cell lines. (b) Western blot analyses showing the effects of apigenin $(0-80 \mu \mathrm{m})$ on the cleavage of poly ADP-ribose polymerase in U1242 MG cells.

$48 \mathrm{~h}$ post-treatment, we observed that at the lower concentrations of 10 and $20 \mu \mathrm{M}$, apigenin showed a cytoprotective effect by exhibiting a low per cent of LDH release compared to the control group of cells. Furthermore, we observed that cells treated with varying concentrations of apigenin for $72 \mathrm{~h}$ exhibited an increase in the release of LDH compared to the untreated control cells. At the 72-h time point, we no longer observed the initial cytoprotective effect of apigenin.

\section{Effects of apigenin on apoptotic signalling}

Poly ADP-ribose polymerase cleavage and $\mathrm{Bcl}-\mathrm{xL}$ protein reduction are standards for the measurement of apoptotic signalling activation. Their presence also indicates the 
(a)
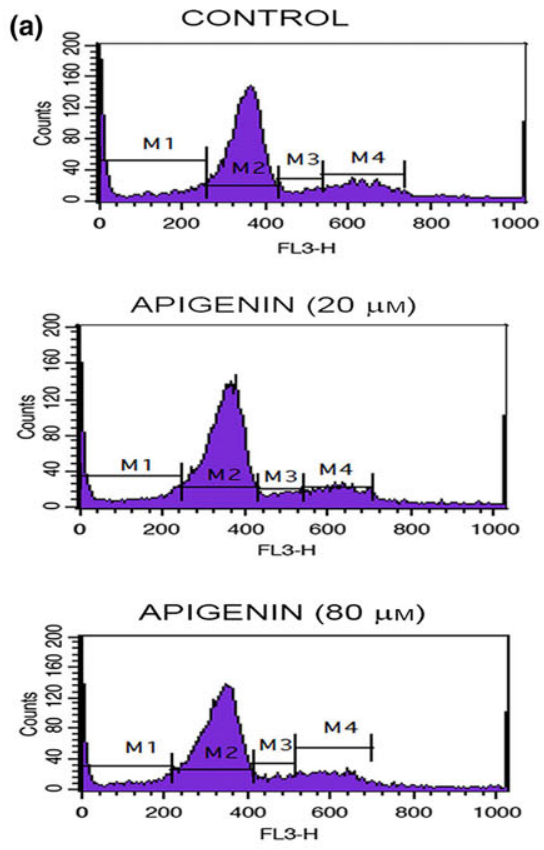
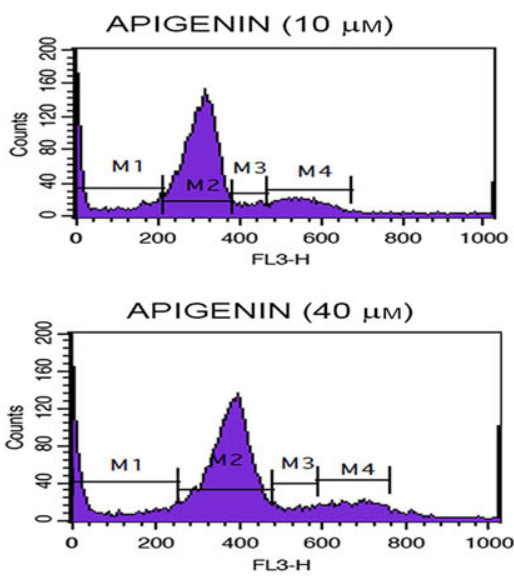

Treatment ( $1 \mathrm{M}) \quad$ G2M Phase (9)

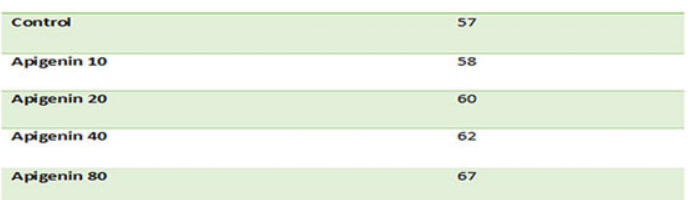

U1242 MG

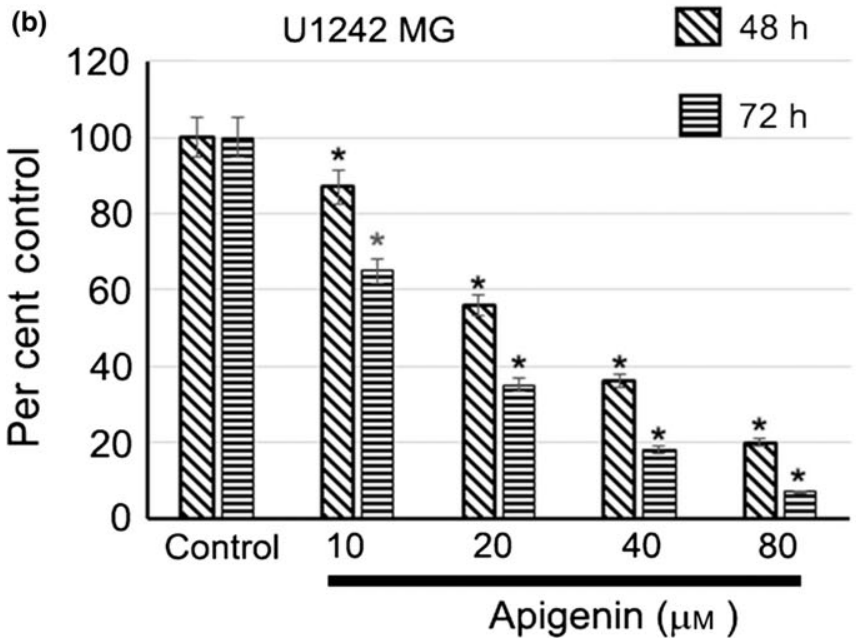

(c)

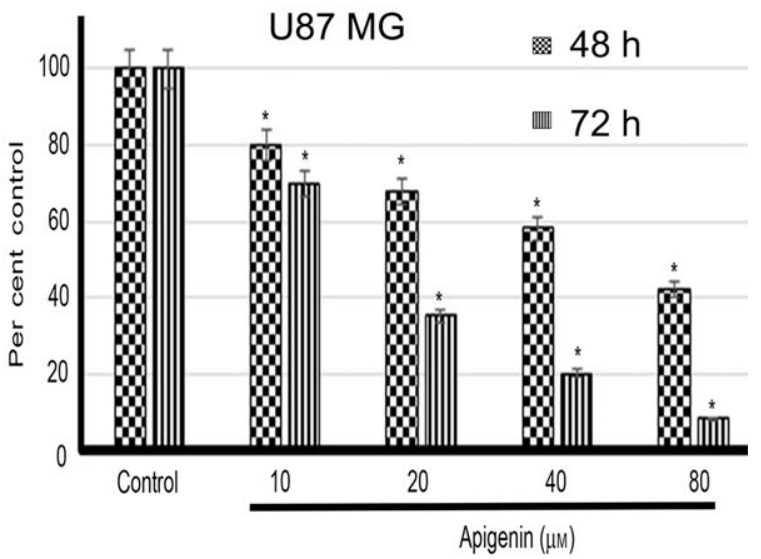

Figure 4 (a) Flow cytometry analyses for U1242 MG cells treated with apigenin (0-80 $\mu \mathrm{M})$. After $72 \mathrm{~h}$, the cells were then stained with propidium iodide and subjected to flow cytometry to analyse the cell cycle distribution. The table (insert) showed the percentage of cells arrested at the G2/M cell cycle check point. (b) Effects of apigenin (0-80 $\mu$ M) on the proliferation of U1242 MG cells as measured by a MTT assay after 48 and $72 \mathrm{~h}$ of treatment. (c) Effects of apigenin $(0-80 \mu \mathrm{M})$ on the proliferation of U87 cells as measured by a MTT assay after 48 and $72 \mathrm{~h}$ of treatment. All data are expressed as the mean \pm SD of experiments. *Denotes significant $(P<0.05)$ difference in proliferation of treated cells compared to untreated control cells. [Colour figure can be viewed at wileyonlinelibrary.com]

activation of pro-apoptotic caspases. In this study, we tested the effects of apigenin-induced apoptosis in glioblastoma cell lines. We investigated the effects of apigenin on the expression of antiapoptotic proteins $\mathrm{Bcl}-\mathrm{xL}$ and PARP cleavage. Treatment with varying concentrations of apigenin $(0-80 \mu \mathrm{M})$ in both U1242 MG and U87 MG cells downregulated the expression of $\mathrm{Bcl}-\mathrm{xL}$ protein as measured by Western blot analyses (Figure 3a). Furthermore, we observed that apigenin treatment induces PARP cleavage in both GBM cell lines. The PARP cleavage observed was concentration-dependent. The data indicate that apigenin inhibits the DNA repair mechanism in these cell lines through the induction of PARP cleavage (Figure 3b). 

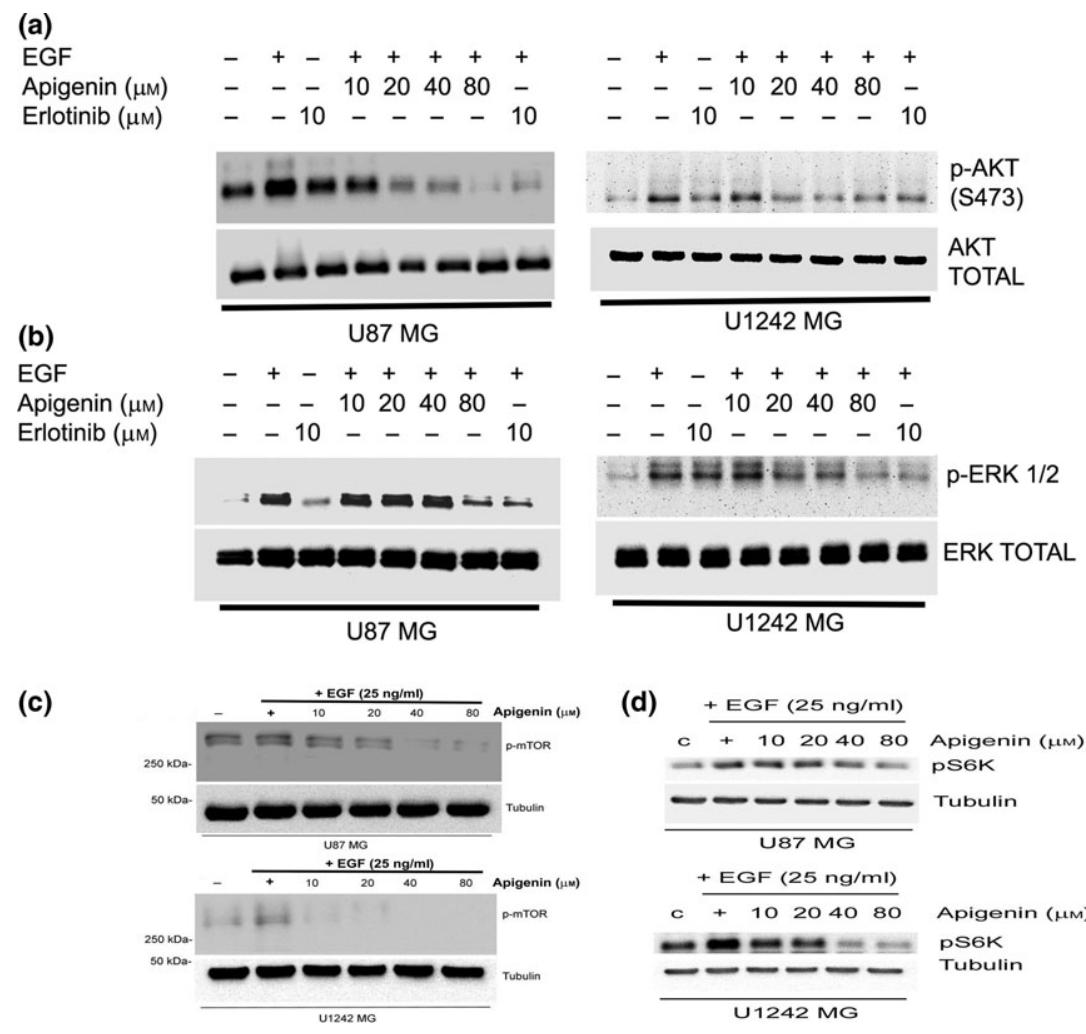

(d)

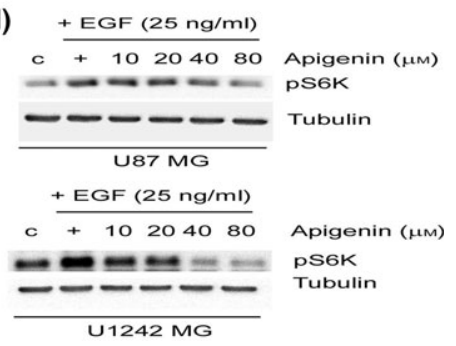

Figure 5 (a) Western blot analyses showing the effects of apigenin (0-80 $\mu \mathrm{m})$ and erlotinib $(10 \mu \mathrm{m})$ on EGF-induced phosphorylation of AKT in U87 and U1242 MG cell lines. (b) Western blot analyses showing the effects of apigenin (0-80 $\mu \mathrm{M})$ and erlotinib (10 $\mu \mathrm{M})$ on EGF-induced phosphorylation of ERK1/2 in U87 and U1242 MG cell lines. (c) Western blot analyses showing the effects of apigenin (0-80 $\mu \mathrm{m})$ on EGF-induced phosphorylation of mammalian target of rapamycin in U87 and U1242 MG cell lines. (d) Western blot analyses showing the effects of apigenin (0$80 \mu \mathrm{M}$ ) on EGF-induced phosphorylation of ribosomal protein 7056 kinase (pS6K) phosphorylation in U87 and U1242 MG cell lines.

\section{Effects of apigenin on glioblastoma cell cycle and proliferation}

To test the effects of apigenin on U1242 MG cell division, we used flow cytometry to measure how it affects the different phases of cell division. Our analysis showed that apigenin primarily caused cell cycle arrest at the G2/M phase of the cell cycle and prevented progression to the S-phase (Figure 4a). When we compared with vehicle control cells $(57 \%)$, with cells treated with apigenin $(20-80 \mu \mathrm{M})$ there was an increase in cells arrested at the G2/M phase $(60-67 \%)$ at the 72 -h time point (see table insert in Figure 4a).

To further ascertain the effect of apigenin on GBM cell proliferation, we used the MTT assay. The MTT assay is widely used to determine the effects of molecules on cell proliferation. U1242 MG and U87 MG GBM cells grown in 96 well plates were treated with increasing concentrations of apigenin. Treatment with apigenin $(0-80 \mu \mathrm{M})$ demonstrated a concentration-dependent and time-dependent decrease in cell proliferation. The assay showed a decrease in the percentage of cells proliferating at each concentration compared with the control, which was considered $100 \%$ proliferation. The antiproliferative potential of apigenin at 48 and $72 \mathrm{~h}$ on the U1242 MG cell is shown (Figure $4 \mathrm{~b}$ ) and U87 MG cells (Figure 4c). This Figure shows a significant $(P<0.05)$ decrease in cell proliferation compared with control.

\section{Effects of apigenin on the epidermal growth factor receptor signalling cascade}

To test and ascertain the possible pathways involved in apigenin-induced decrease in GBM cell proliferation and apoptosis, we tested its effect on EGFR signalling because this pathway is paramount and important for the survival of GBM. Also, apigenin has been shown to affect EGFR signalling in head and neck tumours. To test the effects of apigenin and erlotinib $(10 \mu \mathrm{M})$ on EGFR-mediated signalling in GBM cells, we pretreated U1242 MG and U87 MG cells with apigenin $(0-80 \mu \mathrm{M})$ and erlotinib $(10 \mu \mathrm{M})$ and these cells were then treated 

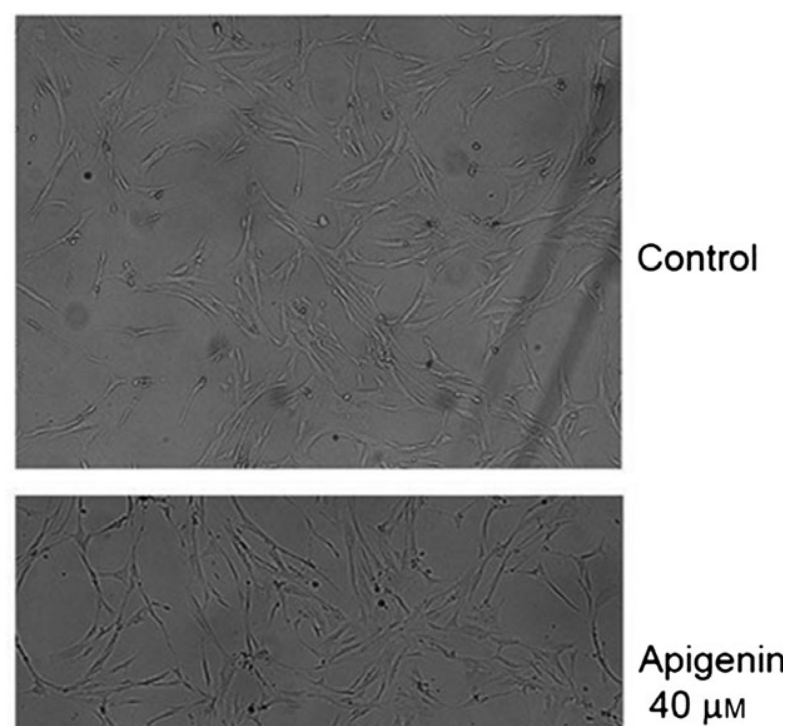

$40 \mu \mathrm{m}$

\section{Normal human astrocytes}

Figure 6 Effects of apigenin $(40 \mu \mathrm{m})$ on the morphology of normal human astrocytes.

with EGF (25 ng/ml) for $15 \mathrm{~min}$. Cell lysates were blotted using Western blot analysis for growth signalling molecules, such as phosphorylated AKT, phosphorylated ERK, mTOR and S6K, that are known pathways downstream of EGFR activation. Western blot analyses showed apigenin caused a concentration-dependent decrease in AKT phosphorylation in both cell lines similar to the effects of erlotinib in the presence of EGF treatment (Figure 5a). Similarly, we observed a decrease in the phosphorylated levels of ERK in U1242 MG cells following apigenin and erlotinib treatments (Figure 5b). ERK phosphorylation in the U87 MG cells was not significantly perturbed by treatment with apigenin compared with erlotinib (Figure 5b). Furthermore, we tested the effects of apigenin pretreatment on mTOR and S6K. We report here that treatment with apigenin downregulated the phosphorylation levels of mTOR (Figure 5c) and S6K (Figure 5d) in both cell lines in the presence of EGF. Overall, the data revealed that apigenin attenuated phosphorylated levels of AKT, mTOR and S6K in both cell lines. This data therefore, suggests a more robust inhibition of the AKT-mTOR signalling pathways as compared to the ERK-MAPK signalling pathways.

\section{Effects of apigenin on normal human astrocytes}

Finally, we tested the effects of apigenin on the morphology of NHA cells. NHA cells grown to about $60 \%$ confluency were treated with DMSO control and apigenin $(40 \mu \mathrm{M})$ for $48 \mathrm{~h}$. At the 48 -h time point, the morphological photomicrograph of the cells was taken using the Nikon NIS Element Imaging software (version 4.0). We did not observe any morphological change in cells treated with apigenin compared with the control cells, suggesting that apigenin had a more pronounced biological activity in cancer cells (Figure 6).

\section{Discussion}

Glioblastoma presents with a variety of therapeutic challenges due to its heterogeneity, invasiveness and resistance to apoptosis. ${ }^{[5,27,28]}$ These effects are promoted by EGFR amplifications, which are the most common oncogenic mutations in GBM. ${ }^{[7]}$ Such amplifications are key to the pathogenesis of GBM and thus present an important target for therapy. Apigenin demonstrated marked inhibition of GBM cells treated with $25 \mathrm{ng} / \mathrm{ml}$ EGF. These in-vitro results demonstrate the promising antitumour activity of apigenin through EGFR signalling inhibition. Our data in Figure 6 showed that apigenin, at the dose tested did not produce any morphological change in the treated NHA cells and untreated control NHA cells. Through cell counts, MTT assays, LDH assays and Hoechst-propidium iodide staining, apigenin displayed its biological relevance as a potential therapeutic agent for cancer treatment. Apigenin inhibited cellular growth and proliferation in both a doseand time-dependent manner. This confirms previous results that demonstrate the therapeutic utility of apigenin in other cancers. ${ }^{[19-23,29]}$ Of particularly importance, apigenin inhibited downstream targets of EGFR signalling as demonstrated by inhibition of AKT phosphorylation as well as $\mathrm{S} 6 \mathrm{~K}$ and mTOR in both cell lines. Activation of the PI3K/AKT pathway through phosphorylation induces cell growth, proliferation and inhibits apoptosis possibly by blocking the effects of pro-apoptotic targets such as Bad and activating pro-survival transcription factor NF$\kappa \mathrm{B} .^{[18,30]}$

Apigenin inhibited ERK phosphorylation in the U1242 cell line but did not modulate ERK phosphorylation in U87 cells. Phosphorylated ERK enhances cell growth, proliferation, differentiation and migration. ${ }^{[31]}$ We observed a robust, more pronounced effects of erlotinib on both AKT and ERK signalling pathways. Taken together, our data on EGFR-mediated signalling could suggest that the biological effect of apigenin on glioblastoma growth may be mediated via the AKT/mTOR signalling. Through these mechanisms, 
apigenin impacted key characteristic signalling molecules mediating EGFR-induced cell proliferation and resistance to apoptosis in both cell lines. This resulted in a decrease in tumour cell viability demonstrated in cell counts, cell proliferation and apoptotic signalling molecules. These effects demonstrate the potential of apigenin to inhibit GBM tumour progression in vitro.

Beyond the effects on the EGFR signalling cascade, apigenin also impacted certain antiapoptotic markers such as Bcl-xL and PARP. ${ }^{[32]}$ Apigenin inhibited Bcl-xL in both cell lines suggesting the possible involvement of cytochrome $\mathrm{C}$ and caspase- 9 activation in apigenin-induced GBM apoptosis. ${ }^{[32]}$ PARP cleavage results in a loss of the DNA repair function. ${ }^{[33]}$ We showed marked increase in PARP cleavage at 40 and $80 \mu \mathrm{M}$ indicating a loss of DNA repair and G2/M cell cycle arrest. We observed a G2/M phase cell cycle arrest with flow cytometry confirming the effect of apigenin on PARP inactivation. Apigenin demonstrated protective effects in the U1242 cell line at lower concentrations in the LDH assays. These protective effects have been demonstrated with other flavonoids and have been hypothesised to be due to antioxidant properties. Additionally, the increase in cleaved PARP shown at higher concentrations of apigenin may play a role in eliminating the protective effects. At the 10 and $20 \mu \mathrm{M}$ concentrations apigenin did not increase PARP cleavage, but at both the 40 and $80 \mu \mathrm{M}$ concentrations it caused a marked increase in cleaved PARP. This loss of DNA repair could be fundamental in the mechanism for inducing apoptosis at the G2/M checkpoint.

\section{Conclusion}

These results provide a picture of the chemotherapeutic potential of apigenin. Our results demonstrate the ability of apigenin to not only inhibit cellular growth and proliferation, but also induce apoptosis in GBM cells. Apigenin markedly inhibited EGFR signalling, which is key to the pathogenesis of GBM. ${ }^{[34,35]}$ Overall, apigenin provides effective tumour suppression through blockade of downstream targets of the EGFR pathway.

\section{Declarations}

\section{Conflict of interest}

The Authors declare no conflict of interest.

\section{Acknowledgements}

We would like to thank Dr William Miller of the Department of Molecular Genetics at the University of Cincinnati for flow cytometry analyses. We would also like to thank Dr Aleda Chen of Cedarville University School of Pharmacy for assistance with statistical analyses. The authors are grateful to Rachel Wilcox and Stacy Lin for technical assistance. This work is supported by a grant from the Cedarville University, School of Pharmacy to Dr Samson Amos.

\section{References}

1. Furnari FB et al. Malignant astrocytic glioma: genetics, biology, and paths to treatment. Genes Dev 2007; 21: 26832710.

2. Haar CP et al. Drug resistance in glioblastoma: a mini review. Neurochem Res 2012; 37: 1192-1200.

3. Louis DN et al. The 2007 WHO classification of tumours of the central nervous system. Acta Neuropathol 2007; 114: 97-109.

4. American Brain Tumor Association. http://www.abta.org (accessed April 4, 2016), Brain Tumor Information: Glioblastoma.

5. Padfield E et al. Current therapeutic advances targeting EGFR and EGFRvIII in glioblastoma. Front Oncol 2015; 5: 1-8.

6. Hatanpaa KJ et al. Epidermal growth factor receptor in glioma: signal transduction, neuropathology, imaging, and radioresistance. Neoplasia 2010; 12: 675-684.

7. Azuaje $\mathrm{F}$ et al. Therapeutic control and resistance of the EGFR-driven signaling network in glioblastoma. Cell Commun Signal 2015; 13: 1-13.

8. Huang $\mathrm{C}$ et al. MAP kinases and cell migration. J Cell Sci 2004; 117: 46194628.

9. Fresno Vara JA et al. PI3K/Akt signaling pathway and cancer. Cancer Treat Rev 2004; 30: 193-204.

10. Phung TL et al. Akt1 and Akt3 exert opposing roles in the regulation of vascular tumor growth. Cancer Res 2015; 75: 40-50.

11. Alberts B et al. Molecular Biology of the Cell, 4th edn [Online]. New York, NY: Garland Science, 2002. Chapter 17, Programmed Cell Death (Apoptosis). http://www.ncbi.nlm.nih.gov/books/NBK 26873/ (accessed April 12, 2016).
12. Pop C, Salvesen GS. Human caspases: activation, specificity, and regulation. J Biol Chem 2009; 284: 21777-21781.

13. Elmore S. Apoptosis: a review of programmed cell death. Toxicol Pathol 2007; 35: 495-516.

14. Weil MK, Chen AP. PARP inhibitor treatment in ovarian and breast cancer. Curr Probl Cancer 2011; 35: 7-50.

15. Tentori L et al. Potential clinical applications of poly (ADP-ribose) polymerase (PARP) inhibitors. Pharmacol Res 2002; 45: 73-85.

16. Sikder MA et al. Apigenin and wogonin regulate epidermal growth factor receptor signaling pathway involved in MUC5AC mucin gene expression and production from cultured airway epithelial cells. Tuberc Respir Dis 2014; 76: 120-126.

17. Escande $\mathrm{C}$ et al. Flavonoid apigenin is an inhibitor of the NAD+ase CD38: implications for cellular NAD+ 
metabolism, protein acetylation, and treatment of metabolic syndrome. Diabetes 2013; 62: 1084-1093.

18. Masuelli L et al. Apigenin induces apoptosis and impairs head and neck carcinomas EGFR/ErbB2 signaling. Front Biosci 2011; 16: 1060-1068.

19. Shukla $\mathrm{S}$ et al. Apigenin induces apoptosis by targeting inhibitor of apoptosis proteins and Ku70-Bax interaction in prostate cancer. Apoptosis 2014; 19: 883-894.

20. Das A et al. Flavonoids activated caspases for apoptosis in human glioblastoma T98G and U87MG cells but not in human normal astrocytes. Cancer 2010; 116: 164-176.

21. Zhu Y et al. Apigenin promotes apoptosis, inhibits invasion and induces cell cycle arrest of T24 human bladder cancer cells. Cancer Cell Int 2013; 13: 54.

22. He J et al. Oral administration of apigenin inhibits metastasis through AKT/P70S6K1/MMP-9 pathway in orthotopic ovarian tumor model. Int $\mathrm{J}$ Mol Sci 2012; 13: 7271-7282.

23. Kuo $\mathrm{CH}$ et al. Apigenin has antiatrophic gastritis and anti-gastric can- cer progression effects in Helicobacter pylori-infected Mongolian gerbils. J Ethnopharmacol 2013; 151: 1031-1039.

24. Cochran DB et al. Degradable poly (apigenin) polymer inhibits tumor cell adhesion to vascular endothelial cells. J Biomed Mater Res B Appl Biomater 2015; 19: 1-10.

25. Zhang $\mathrm{T}$ et al. Apigenin protects blood-brain barrier and ameliorates early brain injury by inhibiting TLR4mediated inflammatory pathway in subarachnoid hemorrhage rats. Int Immunopharmacol 2015; 28: 79-87.

26. Hussaini IM et al. Phorbol 12-myristate 13-acetate induces protein kinase $\mathrm{C}$ eta-specific proliferative response in astrocytic tumor cells. J Biol Chem 2000; 275: 22348-22354.

27. Brennan CW et al. Inhibition of mTOR by apigenin in UVB-irradiated keratinocytes: a new implication of skin cancer prevention. Cell Signal 2016; 28: 460-468.

28. DeAngelis LM. Brain tumors. N Engl J Med 2001; 344: 114-123.

29. Shukla S, Gupta S. Apigenin: a promising molecule for cancer prevention. Pharm Res 2010; 27: 962-978.

30. Cagle P et al. Effect of rosehip (Rosa canina) extracts on human brain tumor cell proliferation and apoptosis. J Cancer Therapy 2012; 3: 23446.

31. Dhillon AS et al. MAP kinase signalling pathways in cancer. Oncogene 2007; 26: 3279-3290.

32. Czabotar PE et al. Control of apoptosis by the BCL-2 protein family: implications for physiology and therapy. Nat Rev Mol Cell Biol 2014; 15: 49-63.

33. Jubin $\mathrm{T}$ et al. The PARP family: insights into functional aspects of poly (ADP-ribose) polymerase-1 in cell growth and survival. Cell Prolif 2016; 49: 421-437.

34. Krempler A et al. An imperfect G2M checkpoint contributes to chromosome instability following irradiation of S and G2 phase cells. Cell Cycle 2007; 6: 1682-1686.

35. Liu $\mathrm{F}$ et al. EGFR mutation promotes glioblastoma through epigenome and transcription factor network remodeling. Mol Cell 2015; 60: 307-318. 